\title{
Evaluation of the parental satisfaction of developmentally delayed pediatric patients undergoing dental surgery with the "pediatric anesthesia parent satisfaction (PAPS)"
} survey

\author{
Mehmet Sargın $^{1} \odot$, Hatice Toprak $^{2} \odot$, Jale Bengi Çelik ${ }^{1} \odot$ \\ ${ }^{1}$ Department of Anesthesiology and Reanimation, Selçuk University School of Medicine, Konya, Turkey \\ ${ }^{2}$ Department of Anesthesiology and Reanimation, Konya Training and Research Hospital, Konya, Turkey
}

\begin{abstract}
Objectives: The aim of the present study was to assess parental satisfaction of developmentally delayed pediatric patients undergoing dental surgery and compare this to satisfaction with anesthesia care for children without developmentally delayed.

Methods: Therefore, two different groups were approached and compared to matching controls. "Pediatric anesthesia parent satisfaction (PAPS)" survey was used to evaluate parental satisfaction in the present study. The PAPS survey was administered to 50 parents of developmentally delayed pediatric patients (Group I) and 30 parents of children without developmentally delayed (Group II). However, due to the shortcomings in the questionnaires, 5 participants from Group I and 4 from Group II were excluded from the study.

Results: In the "Before anesthesia", "After anesthesia", "Hospital team" and "Anesthesia team" parts of survey no statistically significant difference was found between the groups. In the "Before anesthesia" part the lowest score was given in response to Q5 item (The anesthesia team explained to me how my child might feel physically and emotionally after anesthesia and surgery). The mean score of Q5 item was $2.73 \pm 1.77$ in Group I and $2.36 \pm 1.40$ in Group II.

Conclusions: In conclusion, it was found that there is no difference between parental satisfaction of children with developmentally delayed and parental satisfaction of developmentally delayed pediatric patients.

Keywords: Parental satisfaction, pediatric, anesthesia, dental surgery, survey
\end{abstract}

$\mathrm{N}$ owadays, the main purpose of medical procedures is to reduce costs, protect resources and increase patient satisfaction without endangering patient safety [1]. Therefore, patient satisfaction has become an important component of the quality of medical care. Patient-centered outcomes are the primary tool for measuring health service quality and effectiveness [2]. Patient satisfaction improves care quality and communication, resulting in better clinical results [3, 4]. Various patient satisfaction surveys have been developed rapidly in recent years [5-7]. The incentive payments of private insurance companies are shown as the reason for this rapid increase [7, 8]. Based on the rapid progress in information technologies, patients and their relatives have become more important in health care quality and satisfaction and have made

How to cite this article: Sargın M, Toprak H, ÇelikJB. Evaluation of the parental satisfaction of developmentally delayed pediatric patients undergoing dental surgery with the "pediatric anesthesia parent satisfaction (PAPS)" survey. Eur Res J 2020;6(3):225-231. DOI: 10.18621/eurj.486608

Address for correspondence: Mehmet Sargın, MD.,Selçuk University School of Medicine, Department of Anesthesiology and Reanimation, Konya, Turkey.E-mail: mehmet21sargin@yahoo.com 
their choices in this direction $[8,9]$.

Postoperative patient satisfaction is an important measure of hospital care. Because it enables the patient to be evaluated throughout the entire hospitalization period [7, 8]. Children's satisfaction can be difficult to assess or express themselves, so parents' satisfaction in terms of anesthesia can be used as a measure of their satisfaction. Parental satisfaction is closely related to the quality of medical care and communication. Parental satisfaction was evaluated in previous studies [10-12]. The satisfaction rate is closely related to many factors such as accessibility to the physician, communication with the family and emotional state of the family and empathy $[13,14]$.

Evaluation of patient satisfaction in anesthesia services is mixed. There is very little validated satisfaction scale, and there is a lack of pediatric anesthesia [15]. There are also doubts about the widespread use of these scales. Although there are departments related to anesthesia in various surgical care questionnaires, they do not qualify [16]. Also not approved by ASA. Pediatric Anesthesia Parent Satisfaction (PAPS) aimed to eliminate these deficiencies was developed by Milliken-Glabe et al. [17].

The aim of this study was to assess parental satisfaction of developmentally delayed pediatric patients undergoing dental surgery with the "Pediatric anesthesia parent satisfaction (PAPS)" survey and compare this to satisfaction with anesthesia care for children without developmentally delayed.

\section{METHODS}

Institutional ethics committee approval and written consent from the parents of each patient was obtained for the study. Inclusion criteria were children aged $<16$ years, parents able to speak, read and write Turkish, parents willing to participate in this study, and elective procedures under general anesthesia.

"Pediatric anesthesia parent satisfaction (PAPS)" survey was used to evaluate parental satisfaction in the present study. This questionnaire was developed by Milliken-Glabe et al. [17] and which contained 15 closed-ended items, one open-ended items. Responses of the survey were recorded using a 5-point Likert scale: 1 (Disagree very much), 2, 3, 4, and 5 (Agree very much). Closed-ended questions consist of 5 parts:
"Before anesthesia", "Before and after anesthesia", "After anesthesia", "Hospital team" and "Anesthesia team". While evaluating this Likert type scale, we evaluated the highest value as the highest score because it reflects the best satisfaction.

The PAPS survey was administered to 50 parents of developmentally delayed pediatric patients and 30 parents of children without developmentally delayed undergoing dental surgery in the PACU prior to discharge. They had been informed that their answers would not affect the care given to their children. Parents were asked to answer questions regarding their level of satisfaction. In addition to the questionnaire, parents were also asked to specify their demographic characteristics (Age, gender, education level, monthly income of the family, where the family lived ). And also, operation time, nausea and vomiting in PACU, pain score in PACU and shivering in PACU were recorded.

With a 0.65 effect size and $1 / 2$ allocation ratio, (n1/n2) 22/44 subjects were required for an $\alpha$ value of 0.05 and a power of $80 \%$.

\section{Statistical Analysis}

Statistical analyses were performed with SPSS 15.0 software (SPSS Institute, Chicago, IL, USA). The comparisons in both groups were carried out using the Student t-test and Pearson Chi-Square test. Parental satisfaction score between the two groups was evaluated using Student t-test. A $p<0.05$ value was considered statistically significant.

\section{RESULTS}

The PAPS survey was administered to 50 parents of developmentally delayed pediatric patients (Group I) and 30 parents of children without developmentally delayed (Group II) however, due to the shortcomings in the questionnaires, 5 participants from Group I and 4 from Group II were excluded from the study.

Patients' demographic, clinical characteristics are summarised in Table 1, and there were no significant differences between the groups regarding patients' gender, operation time, nausea and vomiting in PACU, pain score in PACU and shivering in PACU ( $p=$ $0.844, p=0.269, p=0.444, p=0.170$, and $p=0.444$, respectively). The mean age of the patients in Group I 
Table 1. Patients' demographic, clinical characteristics

\begin{tabular}{lccc}
\hline & $\begin{array}{c}\text { Group I } \\
(\mathbf{n = 2 6 )}\end{array}$ & $\begin{array}{c}\text { Group II } \\
(\mathbf{n}=\mathbf{4 5})\end{array}$ & p value \\
\hline Age, years & $5.92 \pm 2.86$ & $11.56 \pm 3.81$ & $<\mathbf{0 . 0 0 1}^{\mathbf{a}}$ \\
\hline Gender, M/F, n (\%) & $14(53.8) / 12(46.2)$ & $23(51.1) / 22(48.9)$ & $0.844^{\mathrm{b}}$ \\
\hline Height, cm & $113.65 \pm 17.12$ & $133.16 \pm 22.8$ & $<\mathbf{0 . 0 0 1}^{\mathbf{a}}$ \\
\hline Weight, kg & $21.85 \pm 9.13$ & $35.98 \pm 16.36$ & $<\mathbf{0 . 0 0 1}^{\mathbf{a}}$ \\
\hline Operation time, min & $36.15 \pm 20.99$ & $41.56 \pm 18.88$ & $0.269^{\mathrm{a}}$ \\
Nausea and vomiting in PACU, $\mathrm{n}$ & 0 & 1 & $0.444^{\mathrm{b}}$ \\
\hline Pain score in PACU & $2.46 \pm 1.27$ & $2.09 \pm 0.97$ & $0.170^{\mathrm{a}}$ \\
\hline Shivering in PACU, $\mathrm{n}$ & 0 & 1 & $0.444^{\mathrm{b}}$ \\
\hline
\end{tabular}

Values are given as mean \pm standard deviation or $\mathrm{n}(\%) . \mathrm{M}=$ Male, $\mathrm{F}=$ Female, PACU $=$ Postanesthesia care unit. ${ }^{\text {aStudent }} \mathrm{t}$-test, ${ }^{\mathrm{b}}$ Pearson Chi-Square test

was $5.92 \pm 2.86$ years while in Group II it was 11.56 demographic characteristics are summarised in Table \pm 3.81 years $(p<0.001)$. When the height and weight 2 . There was a statistically significant difference of the patients were compared between the groups, between the groups when the age of the parents was there was a statistically significant difference $(p<$ compared $(p<0.001)$. However, there were no 0.001 and $p<0.001$, respectively). Parents' significant differences between the groups regarding

Table 2. Parents' demographic characteristics

\begin{tabular}{|c|c|c|c|}
\hline & $\begin{array}{l}\text { Group I } \\
(\mathrm{n}=\mathbf{2 6})\end{array}$ & $\begin{array}{c}\text { Group II } \\
(n=45)\end{array}$ & $p$ value \\
\hline Parent age, years & $31.23 \pm 5.25$ & $37.53 \pm 7.10$ & $<0.001^{\mathrm{a}}$ \\
\hline Parent gender, $\mathrm{M} / \mathrm{F}, \mathrm{n}(\%)$ & $6(23.1) / 20(76.9)$ & $5(11.1) / 40(88.9)$ & $0.179^{\mathrm{b}}$ \\
\hline Parent education level, $\mathrm{n}(\%)$ & & & $0.131^{\mathrm{b}}$ \\
\hline Primary schoo & $17(65.3)$ & $39(86.6)$ & \\
\hline High school & $4(15.4)$ & $5(11.1)$ & \\
\hline University & $5(19.2)$ & $1(2.2)$ & \\
\hline Monthly income of the family (TL), $n(\%)$ & & & $0.054^{b}$ \\
\hline 0-1999 TL & $11(42.3)$ & $32(71.1)$ & \\
\hline 2000-4999 TL & $12(46.2)$ & $11(24.4)$ & \\
\hline 5000 and more & $3(11.5)$ & $2(4.4)$ & \\
\hline Where the family live, $\mathrm{n}(\%)$ & & & $0.567^{b}$ \\
\hline City center & $24(92.3)$ & $43(95.6)$ & \\
\hline District & $2(7.7)$ & $2(4.4)$ & \\
\hline
\end{tabular}

Values are given as mean \pm standard deviation or $\mathrm{n}(\%) . \mathrm{M}=$ Male, $\mathrm{F}=$ Female, PACU $=$ Postanesthesia care unit. ${ }^{\mathrm{a} S t u d e n t} \mathrm{t}$-test, ${ }^{\mathrm{b}}$ Pearson Chi-Square test 
surveyed gender and education level of the parent, monthly income of the family, and where the family lived $(p=0.179, p=0.131, p=0.054$, and $p=0.567$, respectively).

Pediatric anesthesia parent satisfaction survey scores are summarised in Table 3. There were Q1, Q2, Q3 and Q5 items in the "Before anesthesia" part and no statistically significant difference was found between the groups ( $p=0.096, p=0.625, p=0.223$ and $p=0.329$, respectively). In the "Before anesthesia" part the lowest score was given in response to Q5 item (The anesthesia team explained to me how my child might feel physically and emotionally after anesthesia and surgery). The mean score of Q5 item was $2.73 \pm 1.77$ in Group I and 2.36 \pm 1.40 in Group II $(p=0.329)$.

There were Q6 and Q7 items in the "After anesthesia" part and no statistically significant difference was found between the groups $(p=0.823$ and $p=0.344$, respectively). Q4 item was the only item included in the "Before and after anesthesia" part, and there was no statistical difference between the groups $(p=0.847)$. In the "Hospital team" part there were Q9, and Q15 items and no statistically significant difference was found between the groups ( $p=0.168$ and $p=0.257$, respectively).

There were Q8, Q10, Q11,Q12, Q13, and Q14 items in the "Anesthesia team" part and no statistically significant difference was found between the groups $(p=0.309, p=0.446, p=0.239, p=0.828, p=0.206$ and $p=0.960$, respectively). In the "Anesthesia team" part the lowest score was given in response to Q13 item [I know who the anesthesiologist (physician) was and his/her role in my child's care]. The mean score of Q13 item was $2.58 \pm 1.15$ in Group I and $2.13 \pm 1.32$ in Group II $(p=0.206)$.

Q16 (Please tell us more about your anesthesia experience) item was open-ended, and 16 parents fill

Table 3. Pediatric anesthesia parent satisfaction survey scores

\begin{tabular}{cccc}
\hline & $\begin{array}{c}\text { Group I } \\
(\mathbf{n = 2 6})\end{array}$ & $\begin{array}{c}\text { Group II } \\
(\mathbf{n = 4 5})\end{array}$ & $\boldsymbol{p}$ value \\
\hline Before anesthesia & & & \\
\hline Q1 & $4.50 \pm 0.86$ & $4.13 \pm 0.12$ & $0.096^{\mathrm{a}}$ \\
\hline Q2 & $4.27 \pm 1.11$ & $4.38 \pm 0.74$ & $0.625^{\mathrm{a}}$ \\
\hline Q3 & $3.92 \pm 1.26$ & $4.27 \pm 1.05$ & $0.223^{\mathrm{a}}$ \\
\hline Q5 & $2.73 \pm 1.77$ & $2.36 \pm 1.40$ & $0.329^{\mathrm{a}}$ \\
\hline Before and after anesthesia & & & \\
\hline Q4 & $4.62 \pm 0.89$ & $4.58 \pm 0.72$ & $0.847^{\mathrm{a}}$ \\
After anesthesia & & & \\
\hline Q6 & $4.23 \pm 0.95$ & $4.18 \pm 0.96$ & $0.823^{\mathrm{a}}$ \\
\hline Q7 & $4.58 \pm 0.36$ & $4.69 \pm 0.79$ & $0.344^{\mathrm{a}}$ \\
\hline Hospital team & & & \\
\hline Q9 & $4.80 \pm 0.23$ & $4.80 \pm 0.54$ & $0.168^{\mathrm{a}}$ \\
\hline Q15 & $4.23 \pm 0.76$ & $4.44 \pm 0.75$ & $0.257^{\mathrm{a}}$ \\
\hline Anesthesia team & & & \\
\hline Q8 & $4.96 \pm 0.19$ & $4.84 \pm 0.56$ & $0.309^{\mathrm{a}}$ \\
\hline Q10 & $4.80 \pm 0.43$ & $4.80 \pm 0.45$ & $0.446^{\mathrm{a}}$ \\
\hline Q11 & $4.38 \pm 1.09$ & $4.64 \pm 0.74$ & $0.239^{\mathrm{a}}$ \\
\hline Q12 & $4.65 \pm 0.84$ & $4.69 \pm 0.51$ & $0.828^{\mathrm{a}}$ \\
\hline Q13 & $2.58 \pm 1.15$ & $2.13 \pm 1.32$ & $0.206^{\mathrm{a}}$ \\
\hline Q14 & $4.65 \pm 0.89$ & $4.64 \pm 0.67$ & $0.960^{\mathrm{a}}$ \\
\hline Val & & \\
\hline
\end{tabular}

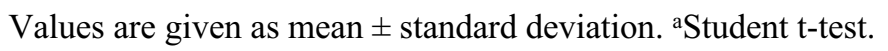


this part in the Group I and 19 parents fill in the Group II. In Group I, 15 out of 16 parents stated extreme satisfaction statements like "Thank you", "We are very satisfied", while one parent stated that "We could not get enough information before anesthesia". In Group II, all 19 parents used satisfaction statements.

\section{DISCUSSION}

In the present study, we have investigated the parental satisfaction of developmentally delayed pediatric patients undergoing dental surgery with the "Pediatric anesthesia parent satisfaction (PAPS)" survey and compare this to satisfaction with anesthesia care for children without developmentally delayed. It has been shown that there are similar characteristics in terms of parents satisfaction. While satisfaction was generally high in both groups, only two items' scores were low. These two items were related to informing parents beforehand by the anesthesia team.

Parents of children with developmental disabilities tend to be well informed about their children's condition and may have high expectations when they arrive at the hospital. Also, it is likely that parents in these two different groups may have differences in informational trends and levels of health professionals.

Patient satisfaction is an important component of the quality of medical care and is used to measure the effectiveness of health care delivery [2]. In pediatric patients, presentation efficiency is mostly evaluated on parental satisfaction. Pediatric anesthesia-related questionnaires have already been performed and are difficult to implement in the routine because of their complexity and length [18]. The PAPS survey is very simple with only 17 questions, and the available parent assessment allows the evaluation of pediatric anesthesia services regardless of the patient's age. Although it was not preferred in our study, the PAPS survey can be applied easily electronically [18-20].

In a study evaluating parental satisfaction of pediatric patients who underwent outpatient surgery, high parental satisfaction was demonstrated similar to our results [21]. However, it was stated that better physical conditions, operation schedules would be made more regularly, and the increase in anesthesia consultations would contribute positively to parental satisfaction.
In a study comparing parental satisfaction in the pediatric sedation unit and operating room, parents reported that the operation room was better informed in comparison to the pediatric sedation unit [22]. Also, it was stated that the operations in the main operating room started at the specified time, while the pediatric sedation unit could be delayed. However, there are no clear statements evaluating the period before and after anesthesia in this study. In our study, parents did not give any feedback on the time of the operation.

In another study evaluating the parental satisfaction of pediatric patients undergoing ambulatory anesthesia, high satisfaction with care before and after anesthesia was noted [23]. Parents need to be more careful about transport and information. While the deficiencies related to preoperative information were revealed in our results, the parents did not mention any disruption related to the transport of the patients.

In a study evaluating the satisfaction of parents with the pediatric surgery patients, Brenn et al. stated that the dissatisfaction reported by the parents was independent of the complication rate and was more because of the operational factors such as waiting times [24].

Chan et al. found a decrease in the level of anxiety in parents and increased parental satisfaction in their parents' education program [25]. In this training, information was given about the roles of midwives during and after anesthesia.

Also, it was indicated that the anxiety, fear, and trauma during anesthesia induction could be reduced by the necessary parental preparation [26]. The majority of the parents prefer to have broad information before their children's surgery, including possible complications [27].

In the literature, it is suggested that some variables such as parental gender, gender, and age of children and previous surgical experiences have important effects on parental anxiety. It was reported that mothers were more anxious than fathers [28]. It was also stated that the children under one year of age and the parents of children with first surgical experience were more anxious [28]. In our study, there was no patient under one year of age. There was an age difference between the groups. The reason for this difference; the fact that children with developmentally delayed ta in older ages allow dental treatment without 
anesthesia is only the developmentally delayed pediatric patients need anesthesia for dental procedures at almost any age. There was no difference in parental gender between the groups, while the majority of the parents were mothers in the present study.

\section{CONCLUSION}

In conclusion, it is seen that there is no difference between parental satisfaction of children with developmentally delayed and parental satisfaction of developmentally delayed pediatric patients. In addition, consistent with the literature, it is seen that patients be informed and their parents are outstanding as a common problem all over the world.

\section{Authors' contribution}

Conception: MS, HT; Design: MS; Supervision: MS, HT; Fundings: MS, HT; Materials: MS, HT; Data collection and/or processing: MS, HT; Analysis and/or interpretation: MS, JBC; Literature review: MS, JBC; Writting: MS, HT, JBC; Critical review: MS, JBC.

\section{Conflict of interest}

The authors disclosed no conflict of interest during the preparation or publication of this manuscript.

\section{Financing}

The authors disclosed that they did not receive any grant during conduction or writing of this study.

\section{REFERENCES}

1. Kassmann BP, Docherty SL, Rice HE, Bailey DE Jr, Schweitzer M. Telephone follow-up for pediatric ambulatory surgery: parent and provider satisfaction. J Pediatr Nurs 2012;27:715-24.

2. Bolus R, Pitts J. Patient satisfaction: the indispensable outcome. Manag Care 1999;8:24-8.

3. Greenfield S, Kaplan S, Ware JE Jr. Expanding patient involvement in care. Effects on patient outcomes. Ann Intern Med 1985;102:520-8.

4. Kaplan SH, Greenfield S, Ware JE Jr. Assessing the effects of physician-patient interactions on the outcomes of chronic disease. Med Care 1989;27(3 Suppl):S110-27.

5. Eagle CJ, Davies JM. Current models of "quality" - an introduction for anesthetists. Can J Anaeth 1993;40:851-62.

6. Darby C, Hays RD, Kletke P. Development and evaluation of the CAHPS Hospital Survey. Health Serv Res 2005;40:1973-6.

7. Giordano LA, Elliot MN, Goldstein E, Lehrman WG, Spencer PA. Development, implementation and public reporting of the HCHAPS survey. Med Care Res Rev 2010;67:27-37.

8. https:// www.cms.gov/ Medicare/ Quality-Initiatives-PatientAssessment-instruments/ HospitalQualityInits/ HospitalHCAHPS. html. Accessed 1 August, 2015.

9. Hospital Compare. www.hospital-compare.hhs.gov. Accessed 1 August, 2015.

10. Odegard KC, Modest SA, Laussen PC. A survey of parental satisfaction during parent present induction of anaesthesia for children undergoing cardiovascular surgery. Paediatr Anaesth 2002;12:261-6.

11. Matziou V, Boutopoulou B, Chrysostomou A, Vlachioti E, Mantziou T, Petsios K. Parents' satisfaction concerning their child's hospital care. Jpn J Nurs Sci 2011;8:163-73.

12. Ebrahim S, Singh S, Parshuram C. Parental satisfaction, involvement, and presence after pediatric intensive care unit admission. J Crit Care 2013;28:40-5.

13. Fumis RR, Nishimoto IN, Deheinzelin D. Families' interactions with physicians in the intensive care unit: the impact on family's satisfaction. J Crit Care 2008;23:281-6.

14. McCormick MC, Escobar GJ, Zheng Z, Richardson DK. Factors influencing parental satisfaction with neonatal intensive care among the families of moderately premature infants. Pediatrics 2008;121:1111-8.

15. Barnett SF, Alagar RK, Grocott MPW, Giannaria S, Dick JR, Moonesinghe SR. Patient satisfaction measures in anesthesia: qualitative systematic review. Anesthesiology 2013;119:452-78. 16. https://www.facs.org/advocacy/quality/cahps/surgical-caresurvey. Accessed 1 August, 2015.

17. Milliken-Glabe SJ, Zuk J, Ziniel SI, Bjur KA, Alvarez M, Szolnoki JM, et al. First steps in validating the pediatric anesthesia parent satisfaction (PAPS) survey. Paediatr Anaesth 2017;27:153-61.

18. Schiff JH, Russ N, Ihringer K. Paediatric Perianesthesia Questionnaire: development and data from eight hospitals across Germany. Br J Anaesth 2011;106:88-95.

19. Odegard KC, Modest SA, Laussen PC. Asurvey of parental satisfaction during parentpresent induction of anaesthesia for children undergoing cardiovascular surgery. Paediatr Anaesth 2002;12:261-6.

20. Iacobucci T, Federico B, Pintus C, de Francisci G. Evaluation of satisfaction level by parents and children following pediatric anesthesia. Pediatr Anesth 2005;15:314-20.

21. Erden IA, Pamuk AG, Ocal T, Aypar U. Parental satisfaction with pediatric day case surgery. Middle East J Anaesthesiol 2006;18:1113-21.

22. Connor MP, Dion GR, Borgman M, Maturo S. The pediatric sedation unit: a prospective analysis of parental satisfaction. Int J Pediatr Otorhinolaryngol 2014;78:2165-8.

23. Boonmak S, Boonmak P, Pothiruk K, Hoontanee N. Parents' satisfaction with pediatric ambulatory anesthesia in northeast of Thailand. J Med Assoc Thai 2009;92:1640-5.

24. Brenn BR, Choudhry DK, Sacks K. Outpatient outcomes and 
satisfaction in pediatric population: data from the postoperative phone call. Paediatr Anaesth 2016;26:158-63.

25. Chan CS, Molassiotis A. The effects of an educational programme on the anxiety and satisfaction level of parents having parent present induction and visitation in a postanaesthesia care unit. Paediatr Anaesth 2002;12:131-9.

26. Hannallah FS. Who benefits when parents are present during anaesthesia induction in their children? Can J Anaesth
1994;4:271-5.

27. Kain ZN, Wang SM, Caramico LA, Hofstadter M, Mayes LC. Parental desire for perioperative information and informaed consent: a two-phase study. Anesth Analg 1997;84:299-306.

28. Litman RS, Berger AA, Chhibber A. An evaluation of preoperative anxiety in a population of parents of infants and childrenundergoing ambulatory surgery. Paediatr Anesth 1996;6:443-7. 